INTERNATIONAL JOURNAL OF RESEARCHES IN BIOSCIENCES, AGRICULTURE AND TECHNOLOGY

(c) VISHWASHANTI MULTIPURPOSE SOCIETY (Global Peace Multipurpose Society) R. No. MH-659/13(N) www.vmsindia.org

\title{
SOL-GEL SYNTHESIS AND METICULOUS CHARACTERIZATION OF ZINC OXIDE NANOPARTICLES
}

\author{
Saurabh Sarkar ${ }^{1}$ and Ratna Sarkar ${ }^{2}$ \\ ${ }^{1}$ Deparment of Mechanical Engineering, Yashwantrao Chavan College of Engineering, Wanadongari Nagpur, \\ Maharashtra, India. 441110 \\ ${ }^{2}$ Department of Chemistry, DRB Sindhu Mahavidylaya, Panchpaoli Nagpur, Maharashtra, India.440017 \\ Email:-saurabhsarkar777@gmail.com
}

\begin{abstract}
This work presents and discusses the study of $\mathrm{ZnO}$ (zinc oxide) as nanoparticles and its idiosyncratic characteristics. Zinc oxide nanoparticles were synthesized employing a simple sol- gel method, with zinc chloride, zinc nitrate and sodium hydroxide as starting materials at room temperature. The synthesized $\mathrm{ZnO}$ nanoparticles were then characterized by X-ray diffraction (XRD), Scanning electron microscopy (SEM), Transmission electron microscope (TEM) and UV-Visible spectroscopy. SEM and TEM images reveal hexagonal morphology of ZnO obtained, with average crystalline size. This was determined from the full width at half maximum of XRD peaks by using DebyeScherrer's Formula. Moreover, interpretation through UV-Visible absorption spectra supported a high absorption confirming its transcendent electrical and optoelectronic properties. It was further mathematically showed that $\mathrm{ZnO}$ nanoparticles can be efficiently utilized as additives in base lubricants to diminish abrasion and wear, enhancing tribological properties.
\end{abstract}

Keywords: Nanoparticles; ZnO nanoparticles; hexagonal morphology; additive; optoelectronic

\section{Introduction}

Nanotechnology is a branch of science which studies fabrication and designing with immense augmentation of nanostructural materials. It is a discipline of matter in size regime of nanometers. In nanolevel, material exhibits unique features with variation in physiochemical attributes. [1-11] Between year 1997 and 2005, investment in nanotechnology research and development by governments around the world soared from $\$ 432$ million to about $\$ 4.1$ billion, and corresponding industry investment exceeded that of governments by 2005 [12-15]. There are diverse sorts of nanoparticles reported in the scope of entire nano literature, e.g., metal nanoparticles, metal oxide nanoparticles, and polymer nanoparticles. Among all these, metal oxide nanoparticles stand out as one of the most versatile materials, owing to their diverse characteristics and functionalities is Zinc oxide nanoparticles [1, 2, $13,14]$. The investigation on $\mathrm{ZnO}$ is catching fire right from the beginning of 1950 to recently, with some reviews on electrical [16], mechanical [1] and optical properties [16] like N-type conductivity, absorption spectra and electroluminescence decay parameter. $\mathrm{ZnO}$ has now become one of most studied material in the last seven years as it presents very interesting properties in nano range synthesis. We recently, carried and studied the synthesis $\mathrm{ZnO}$ nanoparticles along with characterization through XRD, SEM, TEM and UV-Visible spectroscopy. We further studied the influence of $\mathrm{ZnO}$ as additives in base oil and as effective semiconductor.

\section{Experimental details}

\subsection{Materials}

Zinc chloride ( $\mathrm{ZnCl}$, 99\%,Sigma Aldrich, Mumbai, India) Zinc nitrate ( $\mathrm{Zn}\left(\mathrm{NO}_{3}\right)_{2}$,99\%, Merk and Co.,Mumbai,India) and Sodium hydroxide ( $\mathrm{NaOH}, 99 \%$,Sigma Aldrich, Mumbai, India were used in the synthesized experiments. All the chemicals used were of analytical reagent grade obtained from Merck, India. Deionised water (18.2 M $\underline{\Omega} . \mathrm{cm})$, obtained from a Milli-Q water purification system, is used throughout the experiment.

2.2 Synthesis of Zinc Oxide ( $\mathrm{ZnO})$

In a typical synthesis procedure, $\mathrm{ZnO}$ (Zinc Oxide) nanoparticles were prepared by sol-gel method by mixing $0.5 \mathrm{M}$ Zinc chloride, and $0.5 \mathrm{M}$ Zinc nitrate. To this was added $2 \mathrm{M}$ sodium hydroxide solutions slowly, drop wise with vigorous stirring which was continued for $45 \mathrm{~min}$. The resulting white gel (precipitate) obtained was filtered, and washed thoroughly with deionised water for 3 to 4 times. After washing, the gel was allowed to dry at $100^{\circ} \mathrm{C}$ for 10 hours on hot plate in BP110 Laboratory Grade Microwave . This caused $\mathrm{Zinc}$ hydroxide $(\mathrm{ZnOH})$ to decompose into Zinc Oxide $(\mathrm{ZnO})$. The obtained product was calcined at $400^{\circ} \mathrm{C}$ for 5 hours in a muffle furnace ( $\mathrm{C}-601$ version), to remove volatile impurity ,which was later then grind to fine powder using a gate mortar for $15 \mathrm{hrs}$ to obtain the desired $\mathrm{ZnO}$ nanoparticles. 
Reactions

$\mathrm{ZnCl}_{2}+\mathrm{Zn}\left(\mathrm{NO}_{3}\right)_{2}+2 \mathrm{NaOH} \rightarrow \mathrm{Zn}(\mathrm{OH})_{2}+2 \mathrm{HNO}_{3}$ $+2 \mathrm{NaCl}$

$$
\begin{aligned}
& \mathrm{Zn}(\mathrm{OH})_{2} \frac{\mathbf{1 0 0}^{\circ} \mathbf{C}}{\rightarrow} \mathrm{ZnO}+\mathrm{H}_{2} \mathrm{O} \\
& \mathrm{ZnO} \frac{\mathbf{4 0 0}^{\circ} \mathbf{C}}{\rightarrow} \mathrm{ZnO} \text { (calcined) }
\end{aligned}
$$

\section{Results and discussion}

\subsection{Characterization}

3.1.1 X-Ray Diffraction Spectroscopy Analysis The XRD patterns of the prepared sample is shown in Figure 1 .The characterization was carried out using Siemens D500 X-ray Powder Diffraction (XRD) System. The diffraction peaks of all samples exhibited a $\mathrm{ZnO}$ hexagonal wurtzite structure ( $\mathrm{P} 63 \mathrm{mc}$ structure) with high quality crystallinity in good agreement with JCPDS standard number of 36-1451.Table 1 . Shows the average crystalline size of the sample using Debye -Scherrer's equation (Equation 1) and using the full-width at half maximum of (100),(002) and (101) of the X-ray diffraction peaks.

$$
\mathrm{D}=\frac{0.9 \lambda}{\beta \cos \theta}-(\text { Equation } 1)
$$

Where $D$ is the crystallite size $(n m), \lambda$ is the wavelength of incident X-ray (nm), $\beta$ is the full width at half maximum (FWHM) in radians and $\theta$ is the diffraction angle( Half Bragg angle) in degrees. In fig 1 . the diffraction line $\left(\begin{array}{lll}0 & 0 & 2\end{array}\right)$ is narrower than the line $\left(\begin{array}{lll}1 & 0 & 1\end{array}\right)$, and $\left(\begin{array}{lll}1 & 0 & 1\end{array}\right)$ is narrower than the line $\left(\begin{array}{lll}1 & 0 & 0\end{array}\right)$ this indicated an asymmetry in the crystallite shape.The lattice parameters of the crystalline structure was estimated from the following relation (Equation 2) and calculated results are shown in Table 1.

$$
\frac{1}{d_{h k l}^{2}}=\frac{4}{3}\left[\frac{h^{2}+h k+k^{2}}{a^{2}}\right]+\frac{l^{2}}{c^{2}} \quad-(\text { Equation 2) }
$$

where $d_{h k l}$ is the lattice spacing of the $(h k l)$ plane and $a$ and $c$ are the lattice parameters .

From the Table no. 1 it also confirms the porosity of $\mathrm{ZnO}$ nanoparticles since the Bulk density is much lower than X-ray density [8]. (Table 1)

3.1 .2 SEM (Scanning Electron Microscopy)

The synthesized nano $\mathrm{ZnO}$ particles where characterized using Scanning electron microscope (Philips XL 30 ESEM scanning electron microscope), and its morphology was inspected. It demonstrates clearly the formation of spherical $\mathrm{ZnO}$ nanoparticles. The subservient $\mathrm{ZnO}$ particles exhibiting size of $1 \mu \mathrm{m}$, as observed by SEM images, inhere primary $\mathrm{ZnO}$ nanocrystallites having size of about $20 \mu \mathrm{m}$ was estimated by line intersecting method. The primary nanocrystallites are combined to form a larger particle (secondary) by the following two routes [16]: (1) Fusion of one primary crystallite into another. (2) Aggregation of the primary crystallite. The first mechanism gives large crystallite size of micrometer scale The second route results a bigger particle consisting of primary subunits with less porosity. Nucleation and growth rate increases with increase in annealing temperature. In the present work it appears that the aggregation is the dominant mechanism which occurred during the crystallization of gel-network leading to macroscopic $\mathrm{ZnO}$ particles.

Table -1 (XRD Chart)

\begin{tabular}{|l|l|l|l|l|l|l|l|}
\hline Compound & $\mathrm{a}\left(\mathrm{A}^{\circ}\right)$ & $\mathrm{c}\left(\mathrm{A}^{\circ}\right)$ & $\mathrm{v}\left(\mathrm{A}^{\circ 3}\right)$ & $\begin{array}{l}\text { X-ray Density } \\
\mathrm{g} / \mathrm{cm}^{3}\end{array}$ & $\begin{array}{l}\text { Bulk Density } \\
\mathrm{gm} / \mathrm{cm}^{3}\end{array}$ & $\begin{array}{l}\text { Porosity } \\
\%\end{array}$ & $\begin{array}{l}\text { Particle } \\
\text { Size }\end{array}$ \\
\hline $\mathrm{ZnO}$ & 3.2449 & 5.2030 & 47.4443 & 5.6986 & 1.75 & 69.2907 & $\mathbf{2 5} \mathrm{nm}$ \\
\hline
\end{tabular}

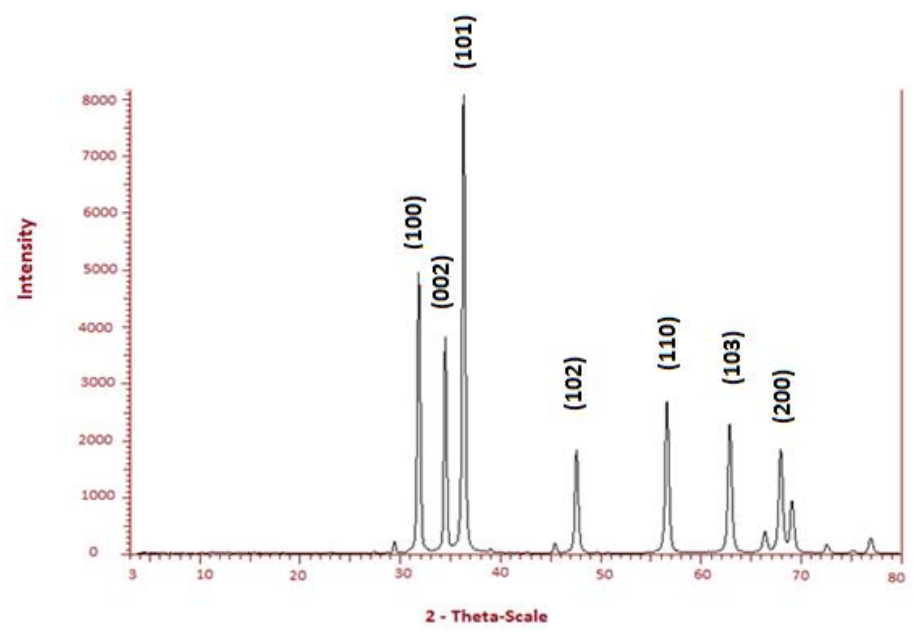

Figure 1. X Ray diffraction pattern of $\mathrm{ZnO}$ nanoparticles 


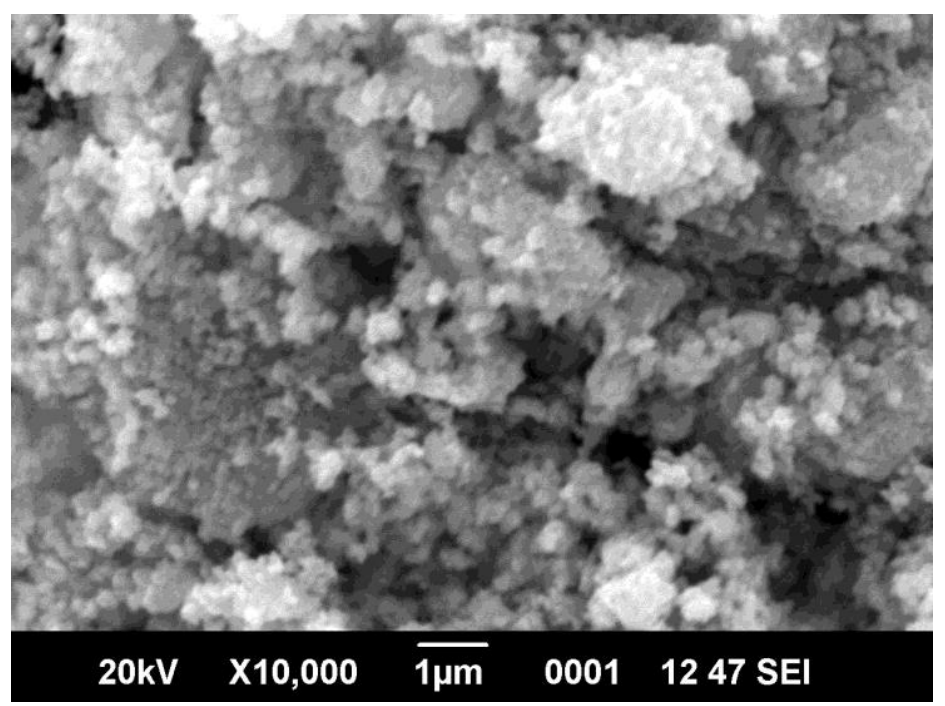

Figure 2 SEM characterization of $\mathrm{ZnO}$ nanoparticles confirming circular morphology and presence of overlapped nanoparticles.

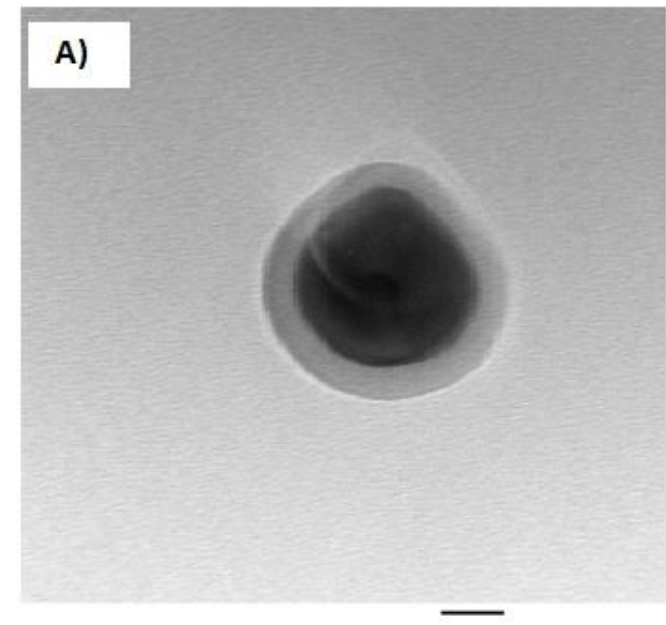

$20 \mathrm{~nm}$ $\mathrm{HV}=80.0 \mathrm{kV}$

Direct Mag: 500000X AMT Camera System

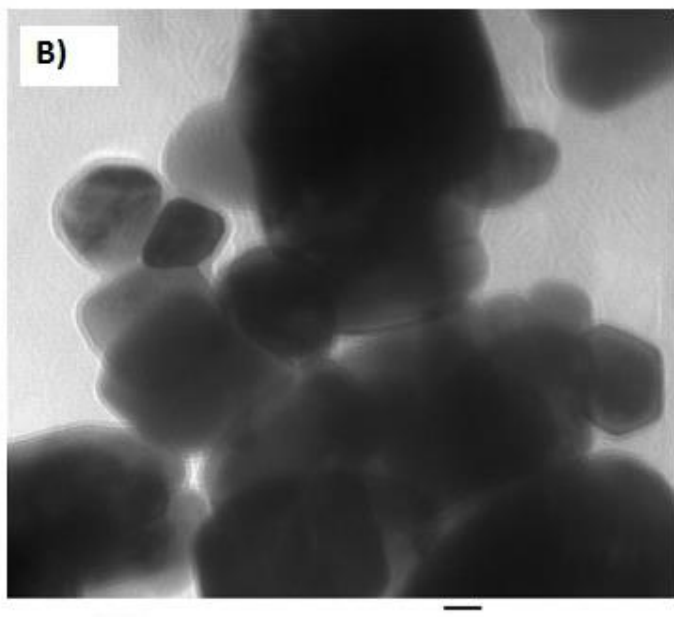

$20 \mathrm{~nm}$

$\mathrm{HV}=80.0 \mathrm{kV}$

Direct Mag: $300000 \mathrm{X}$ AMT Camera System

Figure 3. TEM images of $\mathrm{ZnO}$ nanoparticles showing regular and hexagonal morphology at $400^{\circ} \mathrm{C}$.

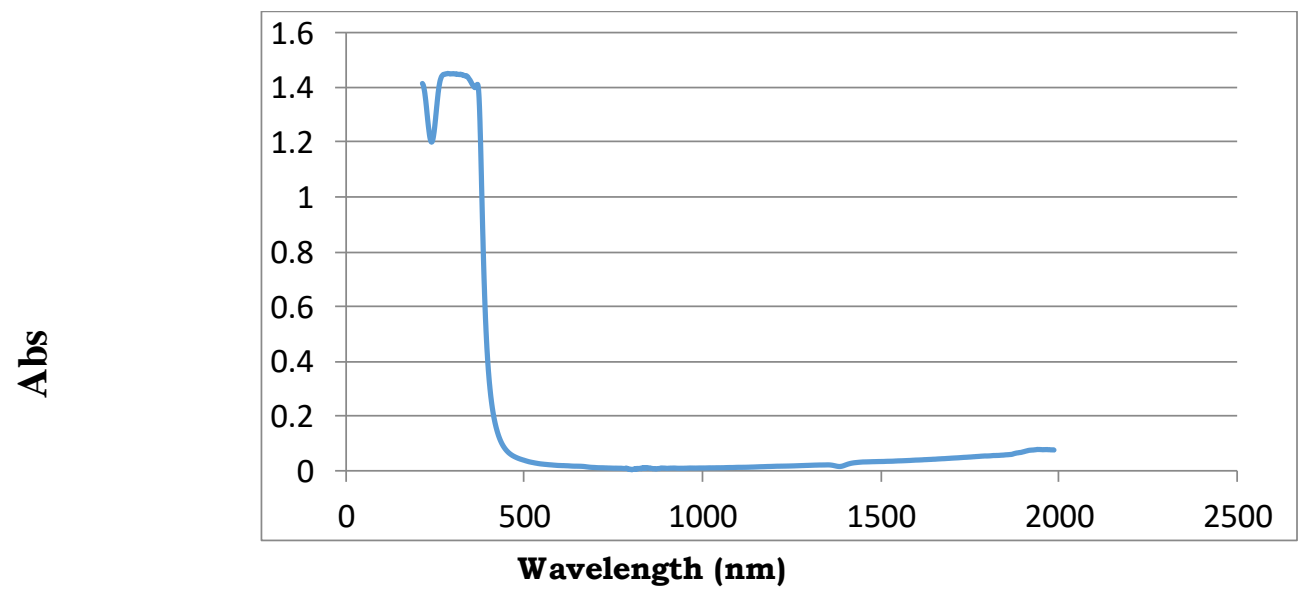

Figure 4. UV- Visible spectrum of $\mathrm{ZnO}$ nanoparticles 
3.1 .3

TEM (Transmission Electron Microscopy)

In order to study deeply the shape and crystallinity of $\mathrm{ZnO}$ nanoparticles, prepared in sodium hydroxide and de-ionised water and to further confirm the XRD patterns, high resolution TEM was performed. Figure shows the TEM images and selected area electron diffraction patterns of $\mathrm{ZnO}$ nanoparticles annealed at $400^{\circ} \mathrm{C}$. This image reveals that the product consist of hexagonal particles with the average size of $21-26 \mathrm{~nm}$ which is in close agreement with that estimated by Scherer formula based on the XRD pattern. From the Figure 4.3(a), \& 4.3(b) the selected area electron diffraction(SAED) shows the crystalline structure and it indicates that the synthesized $\mathrm{ZnO}$ nano particles are not single crystals, rather are the aggregates of several singla crystals.

\subsubsection{UV-Visible Spectroscopy}

In order to explore the optical properties of calcined $\mathrm{ZnO}$ nanoparticles, the optical absorption spectrum was taken using a Beckman DU640 UV/Visible spectrophotometer. The considerable high absorbance attributes towards smaller size of the sample which in turn shows less Rayleigh scattering. Rayleigh scattering (RS) intensities from $\mathrm{ZnO}$ nanoparticles arise from electric-dipole and electric-quadrupole plasmon resonances at the emitted wavelength $[16,17]$.

Considerable conclusions associated with $\mathrm{ZnO}$ nanoparticles can be made by studying its optical properties using UV -visible spectrophotometer $[3,8,9]$.The sample showed absorbance between 300 and 500nm .The behavior obtained in UV/Vis spectrum can occur for variety of reasons, such as inner electrical fields within the crystal, strain caused by imperfection causing deformation of lattice and due to photons carrying inelastic scattering of charge .By considering the wavelength equivalent to the strong cutoff region in the UV/Vis Absorption measurement graph for $\mathrm{ZnO}$ (Fig 4.) the band energy gap of the sample was premeditated(Equation 3).[8-9]

Calculations

$\mathrm{E}=\frac{h * c}{\lambda} \quad-($ Equation 3) here;

$\mathrm{E}$ : Band gap energy, h: Plank's constant $=6.626 *$ $10^{-34}, \mathrm{c}$ : velocity of light $=3^{*} 10^{8} \mathrm{~m} / \mathrm{s}$

Now, $\lambda=425 \mathrm{~nm}$ (from graph Fig 2)i.e. $425^{*} 10^{-9} \mathrm{~m}$ We get $\mathrm{E}=4.6772 * 10^{-19} \mathrm{~J}=2.92 \mathrm{eV}$

Consequently, from above it can be inferred that $\mathrm{ZnO}$ is an exceedingly fine II-VI semiconductor compound .Single crystal exhibits directionally dependent optical properties owing to which it can be brought to bear for modulation of UV radiation. The contemporary example of it is the intended model of $\mathrm{ZnO}$ modulator with a contrast of 70:1 and execution speed of 100ps [18]. This band gap can further be augmented by associating effective doping techniques. Magnesium doped zinc oxide possesses a wide array of sensing spectra between (200-280) $\mathrm{nm}$ which makes it convenient to tune for UV-B and $\mathrm{UV}-\mathrm{C}$ and can be made pertinent for numerous fields such as solar UV radiation monitoring, ultra high temperature flame detection etc [18]. The most important factor responsible for a material to show a better optoelectronic property is the large binding energy, and this property is possessed by Zinc oxide having binding energy of 60 mev which could be attended to and above room temperature due to excitonic recombination [19]. Dye Sesitized Solar Cell (DSSC) is an optoelectronics device that converts light to electrical energy via charge separation in sensitizer dyes absorbed on a wide band gap semiconductor [20], thus it opens up a wide scope for the application of $\mathrm{ZnO}$ nanoparticles for utilizing solar energy.

3.2 Zinc oxide nanoparticles as additives in lubricants

Efficiency of machines can be added on by reduction in energy loss due to friction. Advances in tribology have lead to saving of $11 \%$ of total energy loss in major areas of power generation, transportation and industrial process.

Zinc oxide nanoparticles when employed as lubricant additives have significantly contributed towards better tribological properties[11,7] by exhibiting good attrition and wear reduction features[5].

A very important feature confederated with effective lubricants is the presence of high homogeneity .This is because homogeneity is a direct consequence of the colloidal stability of the lubricant which assists towards reducing erosion between shearing surface[5]. Colloidal stability inversely depends on the deposition rate of the additives at the shearing surface.Hence low deposition rate plays a significant role in imparting better tribological characteristics.

The time taken for $\mathrm{ZnO}$ nanoparticles to deposit is higher than usual micrometer $(\mu \mathrm{m})$ sized particles that are used as additives. This can be interpreted through theoretical analysis using Stokes Law.

Conceding to the XRD and SEM analysis the morphology of $\mathrm{ZnO}$ nanoparticles is spherical which serves as an essential facet for the application of Stoke's Law.

According to Stoke's Law ; (Equation 4) 
$v_{d}=\frac{2 g r^{2}\left(\rho_{n p-} \rho_{f}\right)}{9 \mu_{f}} \quad-($ Equation 4)

Where $; v_{d}$ : velocity of deposition

$\mu_{f}$ : Dynamic viscosity of fluid

g: acceleration due to gravity

r: Size of the particle

$\rho_{n p}$ : Density of the nanoparticle

$\rho_{f}$ : Density of the fluid

Also, $v_{d} \alpha \frac{1}{t}$ (Equation 5) I.e. velocity is inversely proportional to the time of deposition.

From the above two equations (Equation 4 and 5 ) it was concluded that;

Time of deposition of the additives is inversely proportional to the square of the particle size i.e(Equation 6)

t $\alpha \frac{1}{r^{2}}-$ (Equation 6)

From the above theoretical evaluation (Equation 4,5 and 6 ) it can be consummated that for a given base lubricant (fluid) as size of the additive decreases 10 folds i.e. from $\mu \mathrm{m}$ to $\mathrm{nm}$ the deposition time increases 100 folds contributing towards more colloidal stability hence better tribological limits are attained.

The above hence illustrates that lubricant having $\mathrm{ZnO}$ nanoparticles as additives, which has an average size of $25 \mathrm{~nm}$ (from XRD Table 1.), involves much more homogeneity in lubricant than any other additives and hence diminishes the abrasion between the shearing surface.

Through experimental conclusions and setting it has been ascertained that lubricant with $0.5 \%$ $\mathrm{ZnO}$ nanoparticles showed lower deposition and had the best general tribological behavior, but an increase in concentration caused fast deposition which exacerbated the case[4].

\section{Conclusions}

The following conclusions can be drawn from the results presented above:

- SEM characterization confirmed the aggregation as the prevailing agency which ensued during the crystallization of gelnetwork contributing to celestial overlapping $\mathrm{ZnO}$ particles.

- TEM outcomes reveal that Zinc oxide nanoparticles

displays hexagonal morphology confirming the

crystalline

wurtzite structures with space group P6зmc.

- XRD

analysis confirms formation of pure $\mathrm{ZnO}$

from sol- gel process with the diffraction peaks corresponding to $\mathrm{ZnO}$ hexagonal wurtzite structure. High quality crystallinity with lattice parameters $\mathrm{a}=3.2449\left(\mathrm{~A}^{0}\right)$ and $\mathrm{c}=5.2030\left(\mathrm{~A}^{0}\right)$ and affirmative porosity is ascertained.
- $\mathrm{ZnO}$ nanoparticles when employed as additives in lubricants sh ows diminution in depreciation and attrition under controlled concentration. Decrease in the deposition rate of the nanoadditives contributed towards better tribolog ical properties.

- UV-spectrometer evaluation confirmed that $\mathrm{ZnO}$ can be drawn on as excellent semiconducting composite a $\mathrm{s}$ it possesses a promising band gap of 2.92 $\mathrm{eV}$ also permitting it to be applied in electrical and optical industrie s.

\section{References}

[1] I. Kontopoulou, A. Angelopoulou and N. Bouropoulos, $\mathrm{ZnO}$ spherical porous nanostructures obtained by thermal decomposition of Zinc Palmitate, Materials Letters, http://dx.doi.org/10.1016/j.matlet.201 5.11 .110

[2] Abdulaziz Bagabas, Ahmad Alshammari, Md. And Hendrilk Kosslick roomtemperature synthesis of zinc oxide nanoparticles in different media and their application in cyanide photo degradation, Nanoscale Research Letters (2013).

[3] S.Suwanboon and P.Amornpitoksuk .Preparation of $\mathrm{Mg}$-doped $\mathrm{ZnO}$ nanoparticles by mechanical milling and their optical properties.Procedia Engineering 32 (2012)821-826.

[4] A. Hernandez Battez, R.Gonzalez, J.L Viesca, J.E Fernandez, J.M Diaz Fernandez, A.Machado, R.Chou, J.Riba. CuO, $\mathrm{ZrO}_{2}$ and $\mathrm{ZnO}$ nanoparticles as antiwear additives in oil lubricants.

[5] Mustafa Akbulut. Nanoparticles -Based lubrication Systems.Volume 1.Issue $1.1000 \mathrm{e} 101$.

[6] Ronald W Armstrong .The Hardness of strength, properties of WC-Co composites.Materials 2011, 4, 12871308.

[7] Enhancing lubricant properties by nanoparticle additives Sheida Shahnazar, Samira Bagheri* , Sharifah Bee Abd Hamid Nanotechnology \& Catalysis Research Centre (NANOCAT), IPS Building, University of Malaya, 50603 Kuala Lumpur,

[8] Surabhi Siva Kimar, Putcha Venkateswarlu, Vanda Ranga Rao and Gollapalli Nagewara Rao synthesis, characterization and optical properties of zinc oxide nanoparticles International Nano Letters 1-6 (2013 
[9] J Arbiol, Q Xiong ,Semiconductor Nanowires :Materials, synthesis, characterization and application, Woodhead Publishing Series in Electronic and Optical Materials, Woodhead Publishing, 1782422536, 9781782422532,year:2015, $1^{\text {st }}$ edition, pages $572 / 0$.

[10] Roles of nanoparticles in oil lubrication, Wei Daia, Bassem Kheireddin ${ }^{b}$, Hong Gao $^{\text {b }}$ Hong Lianga, Tribology International, Volume 102, October 2016, Pages 88-98

[11]Y.-Z. Hu, T.-B. Ma, Tribology of Nanostructured Surfaces ,Comprehensive Nanoscience and Technology, Volume 3, 2011, Pages 383418

[12] D. Vogel, P. Krüger and J. Pollmann, Ab initio electronic-structure calculations for II-VI semiconductors using selfinteraction-corrected pseudopotentials Physics. Review., 52 (1995) 14316-1431

[13] Tammy P. Chou, Qifeng Zhang, Glen E. Fryxell, Guozhong Cao, , Hierarchically Structured ZnO Film for Dye-Sensitized Solar Cells with Enhanced Energy Conversion Efficiency , Advanced. Materials, 19 (2007)2588-2592.

[14] Seema Rani,PoonamSuri, P.K. Shishodia, R.M. Mehra Study of $\mathrm{ZnO}$ and
$\mathrm{Mg}$ doped $\mathrm{ZnO}$ nanoparticles by sol-gel process,AIP Conference proceedings, 92,(2008)1639-1645.

[15] NSTC/CoT/NSET, NNI Supplement to the President's 2017 Budget, NNI Publications and Reports NNI Budget , March. 312016

[16] A.R. Hutson, Hall Effect Studies of Doped Zinc Oxide Single Crystals Phys.Rev., 108 (1957)222-230.

[17] G.Heiland, E.Mollwo,F.Stockmann, An Empirical Study on Structural, Optical and Electronic Properties of $\mathrm{ZnO}$ Nanoparticles ,Solid State Phys.,8(1959)193-196

[18] Z. L. Wang and Z. C. Kang, Functional and Smart Materials Structural Evolution and Structure Analysis, Plenum press,(1998)465.

[19] B. K. Meyer, H. Alves, D. M. Hofmann, W. Kriegseis et al., Bound exciton and donor - acceptor pair recombinations in $\mathrm{ZnO}$ Phys. Stat. Sol.,241(2004)231-260.

[20] C. Jagadish and S. J. Pearton, Zinc Oxide Bulk, Thin Films and Nanostructures Processing, Properties and Application, Edited by:Chennupati Jagadish and Stephen Pearton ISBN: 978-0-08-044722-3, Elsevier (2006). 